\title{
Effects of Various Binders on Supercapacitor Performances
}

\author{
Zhentao Zhu ${ }^{1,2}$, Shuihua Tang ${ }^{1,2, *}$, Jiawei Yuan ${ }^{1,2}$, Xiaolong Qin $^{1,2}$, Yuxiao Deng ${ }^{1,2}$, Renjie $Q u^{1,2}$, \\ Geir Martin Haarberg ${ }^{3, *}$ \\ ${ }^{1}$ State Key Lab of Oil and Gas Reservoir Geology \& Exploitation, Southwest Petroleum University, \\ Chengdu 610500, China \\ ${ }^{2}$ School of Materials Science and Engineering, Southwest Petroleum University, Chengdu 610500, \\ China \\ ${ }^{3}$ Department of Materials Science and Engineering, Norwegian University of Science and Technology, \\ Trondheim 7491, Norway \\ *E-mail: spraytang@ hotmail.com, geir.martin.haarberg@ntnu.no
}

doi: $10.20964 / 2016.10 .04$

Received: 22 June 2016 / Accepted: 25 July 2016 / Published: 6 September 2016

Supercapacitor performances are influenced by binder types and contents in the electrodes. The electrochemical performances of activated carbon (AC) with Nafion, poly(tetrafluoroethylene) (PTFE) and poly(vinylidenedifluoride) (PVDF) and different contents of each binder were investigated by cyclic voltammetry (CV), galvanostatic charge discharge (GCD) and electrochemical impedance spectroscopy (EIS). The optimal content of binder in the electrode is $10 \mathrm{wt} \%$ for Nafion and PTFE, but only $5 \mathrm{wt} \%$ for PVDF. The specific capacitances of the AC electrodes with optimal content of Nafion, PTFE and PVDF are respectively 131.3, 156.6 and $160.6 \mathrm{~F} \mathrm{~g} \mathrm{~g}^{-1}$; their corresponding specific capacitances retain $87 \%, 91 \%$ and $79.6 \%$ after $2000 \mathrm{CV}$ cycles with a scan rate of $200 \mathrm{mV} \mathrm{s}^{-1}$. Therefore, PTFE is the best suitable binder for supercapacitors and its optimal content is $10 \mathrm{wt} \%$.

Keywords: supercapacitor; activated carbon; Nafion; PTFE; PVDF; binder

\section{$\underline{\text { FULL TEXT }}$}

(C) 2016 The Authors. Published by ESG (www.electrochemsci.org). This article is an open access article distributed under the terms and conditions of the Creative Commons Attribution license (http://creativecommons.org/licenses/by/4.0/). 